\title{
Risk factors, types and outcomes of arterial ischemic stroke in Polish pediatric patients: a retrospective single-center study
}

\author{
Beata Sarecka-Hujar ${ }^{1}$, Ilona Kopyta ${ }^{2}$, Dorota Raczkiewicz ${ }^{3}$
}

\begin{abstract}
${ }^{1}$ Department of Pharmaceutical Technology, School of Pharmacy with the Division of Laboratory Medicine in Sosnowiec, Medical University of Silesia in Katowice, Poland ${ }^{2}$ Department of Pediatric Neurology, School of Medicine, Medical University of Silesia, Katowice, Poland

${ }^{3}$ Institute of Statistics and Demography, Warsaw School of Economics, Warsaw, Poland
\end{abstract}

Submitted: 26 June 2017

Accepted: 14 October 2017

Arch Med Sci 2021; 17 (1): 62-70

DOI: https://doi.org/10.5114/aoms.2017.71805

Copyright (c) 2018 Termedia \& Banach

\section{Abstract}

Introduction: Various neurological complications may occur as a consequence of arterial ischemic stroke (AIS) and have an impact on daily activity of the patients, costs of their medical care and rehabilitation. The aim of this study was to analyze risk factors, stroke symptoms and post-stroke consequences in Polish pediatric patients depending on stroke subtype.

Material and methods: We retrospectively reviewed 77 children under the age of 18 years following their first AIS. Patients were white, Polish Caucasians, recruited in the Department of Pediatric Neurology at the Medical University of Silesia in Katowice (Poland). Statistical analysis was performed using Statistica 12.0.

Results: Gender differed significantly between stroke subgroups $(p=0.030)$. The presence of focal cerebral arteriopathy (FCA) and chronic diseases was associated with type of AIS ( $p=0.003$ and $p=0.050$, respectively). An outcome without neurological deterioration (normal outcome) was observed in $43 \%$ of children with lacunar anterior circulation infarct (LACI). Hemiparesis was present in almost all children with total anterior circulation infarct (TACI), in two thirds of children with partial anterior circulation infarct $(\mathrm{PACl})$ and in almost $50 \%$ of children with $\mathrm{LACl}$ or posterior circulation infarct (POCI). In every child with hemiplegia the stroke symptom evolved into hemiparesis at follow-up. Additionally, patients with a normal outcome were older at the time of AIS than those with at least one neurological consequence $(\mathrm{OR}=0.894, p=0.034)$.

Conclusions: The presence and number of neurological outcomes depend on stroke subtypes. A relation between the presence of post-stroke deficits and age at onset was observed. The odds of deficit after ischemic stroke decreases by an average of $10.6 \%$ if the child is 1 year older at the time of AIS.

Key words: arterial ischemic stroke, post-stroke outcome, focal cerebral arteriopathy, post-stroke seizures, pediatric patients.

\section{Introduction}

Arterial ischemic stroke (AIS) is a rare, heterogeneous disease in which multiple risk factors have an impact on its development. The pathology and the impact of potential risk factors of childhood AIS are still unclear.

\author{
Corresponding author: \\ Beata Sarecka-Hujar PhD \\ Department of \\ Pharmaceutical Technology \\ School of Pharmacy \\ with the Division \\ of Laboratory Medicine \\ Medical University of Silesia \\ 3 Kasztanowa St \\ 41-200 Sosnowiec, Poland \\ E-mail: beatasarecka@poczta. \\ onet.pl
}


The most commonly reported states predisposing to AIS in childhood are central nervous system (CNS) arteriopathies, traumas, infections, cardiac diseases, metabolic diseases and mitochondrial diseases, with approximately half of all cases being cryptogenic $[1,2]$. In adults, atherosclerosis is the main cause of most strokes.

The clinical manifestation of AIS depends on the localization of CNS lesions. Circulation disorders in the intracranial artery and central cerebral artery are characterized by paresis, less paralysis, central paresis or paralysis of the facial nerve and aphasia. Sometimes the focal symptoms are accompanied by headaches, rarely by seizure. If, however, disorders are related to the posterior vertebrae of cerebral vascularization, the features of the cerebellar syndrome will predominate among the clinical symptoms. The location of vascular lesions in patients with AIS has also been a contributor to the commonly used classification of ischemic stroke [3].

A history of pediatric AIS is related to various neurological consequences such as motor impairment (the most common is hemiparesis), seizures or intellectual delay [1, 2]. Therefore, the problem of post-stroke deficits is noteworthy because of their impact on daily activity as well as the costs of medical care and rehabilitation. Ischemic stroke occurring in the perinatal period influences cognitive and behavioral deficits, which become more evident during the subsequent years of life [4]. Earlier studies have reported that post-stroke cognitive problems may be associated with stroke subtypes [4], or epilepsy, since the presence of seizures limits plasticity of the developing brain [5].

In the present study we analyzed the frequencies of risk factors, stroke symptoms and poststroke consequences in Polish pediatric patients depending on stroke subtype.

\section{Material and methods}

\section{Study group}

The study was retrospective and based on 77 patients recruited in the Department of Pediatric Neurology at the Medical University of Silesia in Katowice (Poland) between 2002 and 2012. The inclusion criteria for the study group were: first arterial ischemic stroke; age at onset up to 18 years, white Caucasian. The exclusion criterion from the study group was death after the first AIS or during the recurrence of stroke.

\section{Neurological and cardiology examinations}

A detailed neurological examination of all patients in the acute phase of the disease and at follow-up was performed. Children also underwent cardiology (electrocardiography, ultrasound cardi- ography) and neuroimaging studies with computed tomography and/or magnetic resonance imaging.

Focal cerebral arteriopathy was defined according to Amlie-Lefond et al. criteria [6] as focal stenosis with abnormalities of the arterial wall not attributed to specific diagnoses such as moyamoya, arterial dissection, vasculitis, or post-varicella angiopathy.

The following heart diseases were diagnosed in the recruited patients: common ventricle, sponge cardiomyopathy, mitral valve defect, Ebstein's anomaly and congenital rubella syndrome.

Chronic diseases or congenital malformations occurring in the study of patients included: arterial hypertension, moyamoya disease, Hirschsprung's disease, nephrotic syndrome, Schimke syndrome, thrombocytopenia, type I diabetes, MELAS syndrome (mitochondrial encephalomyopathy, lactic acidosis, and stroke-like episodes), epilepsy (with the onset in the first year of life), adaptive disorders and recurrent respiratory infections.

\section{Clinical manifestation of arterial ischemic stroke}

Arterial ischemic stroke was identified by the World Health Organization's International Classification of Diseases. The stroke subtypes were evaluated according to the Oxfordshire classification into partial anterior circulation infarct (PACl), posterior circulation infarct (POCI), lacunar anterior circulation infarct ( $\mathrm{LACl})$ and total anterior circulation infarct (TACI) [7].

In the present group of patients the following most frequently observed neurological symptoms of AIS were analyzed: hemiplegia, hemiparesis, nerve VII paralysis, disturbances of consciousness, headache and dizziness, aphasia and convulsions.

\section{Neurological consequences of arterial ischemic stroke at follow-up}

At the follow-up, the following consequences of AIS were analyzed: hemiparesis, seizures, aphasia and other movement disorders. Post-stroke seizures in pediatric patients with AIS were defined according to Beslow et al. [8] as: early/acute symptomatic seizures (up to 7 days after stroke onset), remote symptomatic seizures (beyond 7 days from stroke presentation), and at least two recurrent, not provoked, seizures occurring after the acute phase of stroke. In the present analysis the term 'seizures' was used in relation to all patients who experienced any type of seizures, early or late, as well as 'normal outcome' for outcomes without neurological deterioration.

\section{Statistical analysis}

Statistical analysis was performed using Statistica 12.0 software (STATSOFT; Statistica, Tulsa, OK, 
USA). Mean values $(M)$ and standard deviations $(S D)$ were estimated for continuous variables, or absolute numbers $(n)$ and relative numbers (\%) of occurrence of items of categorical variables. The Kruskal-Wallis $\mathrm{H}$ test was used to compare continuous variables between four types of AIS. The Mann-Whitney $U$ test was used to compare continuous variables between the children with a normal outcome and the children with at least one neurological consequence. The stochastic independence $\chi^{2}$ test with Yates's correction was used to compare categorical variables between stroke subtypes as well as between the normal outcome group and the children with at least one consequence. Odds ratio (OR) estimates were used for occurrence of at least one neurological consequence vs. no neurological consequence, with age as the independent variable. In order to interpret it, an OR was calculated and expressed as a percentage. The significance level was set at $p \leq 0.05$ in all of the statistical tests.

\section{Results}

\section{Risk factors of arterial ischemic stroke depending on stroke subtypes}

We analyzed 77 children with AIS, of whom 25 (32\%) had TACl subtype, 23 (30\%) had LACl, 19 (25\%) had $\mathrm{PACl}$ and 10 (13\%) had POCl stroke subtype. Table I shows basic characteristics of the study group as well as risk factors associated with AIS in children. In the study group, most children with $\mathrm{POCl}(90 \%)$ and $\mathrm{TACl}(68 \%)$ stroke subtypes were male, whereas $\mathrm{LACl}$ and $\mathrm{PACl}$ occurred in girls and boys with similar frequency. The age of examined children with AIS ranged from 1 to 18 years old ( $8.3 \pm 5.4$ on average), and age did not significantly differ between stroke subtypes at onset.

There were significant differences between types of AIS and seasons of the year at which the AIS occurred. The TACl subtype appeared most frequently in the summer, $\mathrm{LACl}$ during winter or spring, and $\mathrm{PACl}$ in the winter or autumn.

When we analyzed the position of the patient's body at onset of AIS we found that $44 \%$ of children were sleeping, 32\% were walking, $21 \%$ were sitting and $3 \%$ were standing. However, body position was not associated with stroke subtypes.

Most children with AIS obtained 10 Apgar points after birth (38\%), 24\% were scored with 9 points, $28 \%$ with 8 points, $9 \%$ with 7 points, and one child with 6 points. Almost all the examined children with AIS were born at the full term of pregnancy (from the $38^{\text {th }}$ to $40^{\text {th }}$ week of pregnancy), there being only 1 child who was born in the $35^{\text {th }}$ week of pregnancy. In $19 \%$ of children with AIS there was a history of complicated pregnancy and $6 \%$ presented with low birth weight (below $2500 \mathrm{~g}$ ).
Stroke subtype was not associated with Apgar points, birth weight, fetal age, or complications of pregnancy. In $13 \%$ of children, there was a history of upper respiratory infection before AIS; however, its occurrence did not differentiate stroke subgroups.

On the other hand, we observed that focal cerebral arteriopathy (FCA) and chronic diseases were associated with type of AIS. Focal cerebral arteriopathy was present in most children with TACI (80\%) and $\mathrm{PACl}(79 \%)$ subtypes, in $50 \%$ children with $\mathrm{POCl}$, and was less common in children with $\mathrm{LACl}$ (35\%). Chronic diseases coexisted in $43 \%$ of children with $\mathrm{PACl}, 36 \%$ with $\mathrm{TACl}, 22 \%$ with $\mathrm{POCl}$, and were least common in children with LACI (one child).

\section{Characteristics of the clinical presentations of arterial ischemic stroke depending on stroke subtype}

Table II presents the number of infarct foci and locations of morphological changes as well as the frequency of AIS symptoms in the analyzed pediatric patients. We observed that one infarct focus was present in almost all children with $\mathrm{LACl}$ and $\mathrm{PACl}$ subtypes, in $71 \%$ of children with $\mathrm{TACl}$ and in half of patients with $\mathrm{POCl}$. Two infarct foci were present in one third of patients with $\mathrm{POCl}$ subtype, in every 8 patients with $\mathrm{TACl}$, in 1 patient with $\mathrm{PACl}$ and in one with $\mathrm{LACl}$. Three or more infarct foci occurred in almost $17 \%$ of patients with TACl and in 1 child with $\mathrm{POCl}(11 \%)$. We also found that the number of locations of morphological changes significantly differentiated stroke subtypes. A single location of the morphological changes, i.e. the temporal lobe, was present in most children with $\mathrm{LACl}(86 \%)$ and $\mathrm{POCl}(80 \%)$, and in $61 \%$ of children with $\mathrm{PACl}$. By contrast, in most children with $\mathrm{TACl}$ subtype several locations of morphological changes were observed (61\%).

In the analysis of AIS symptoms we found that hemiplegia was significantly associated with stroke subtype. It was most frequent in children with $\mathrm{TACl}$ stroke (33\%) while none of the children with $\mathrm{POCl}$ had hemiplegia because of the focus localization. Symptoms other than hemiplegia did not differentiate any of the analyzed subgroups of patients. Hemiparesis was present in $85 \%$ of the total study group, nerve VII paralysis in $57 \%$, disturbances of consciousness in $72 \%$, headache and dizziness in 32\%, aphasia in $37 \%$ and convulsions in $16 \%$. Other symptoms were significantly more common in children with $\mathrm{POCl}$ stroke subtype (90\%) compared to children with other subtypes.

\section{Neurological deficits following pediatric arterial ischemic stroke}

Neurological outcomes following pediatric AIS are shown in Table III. The number, type and 
Table I. Factors associated with AIS in children and stroke subtypes

\begin{tabular}{|c|c|c|c|c|c|c|}
\hline Parameter & Total & $\mathrm{LACl}$ & $\mathrm{TACl}$ & $\mathrm{PACl}$ & $\mathrm{POCl}$ & $P$-value \\
\hline Sex, $n(\%):$ & & & & & & 0.030 \\
\hline Girls & $32(41.56)$ & $13(56.52)$ & $8(32.00)$ & $10(52.63)$ & $1(10.00)$ & \\
\hline Boys & $45(58.44)$ & $10(43.48)$ & $17(68.00)$ & $9(47.37)$ & $9(90.00)$ & \\
\hline Age, mean \pm SD [years] & $8.3 \pm 5.4$ & $9.0 \pm 4.8$ & $8.5 \pm 5.5$ & $6.7 \pm 5.1$ & $8.8 \pm 7.1$ & 0.330 \\
\hline Season of the year, $n(\%)$ : & & & & & & 0.045 \\
\hline Winter & $25(33.78)$ & $7(31.82)$ & $6(24.00)$ & $8(44.44)$ & $4(44.44)$ & \\
\hline Spring & $16(21.62)$ & $8(36.36)$ & $6(24.00)$ & $2(11.11)$ & $0(0.00)$ & \\
\hline Summer & $16(21.62)$ & $5(22.73)$ & $8(32.00)$ & $1(5.56)$ & $2(22.22)$ & \\
\hline Autumn & $17(22.97)$ & $2(9.09)$ & $5(20.00)$ & $7(38.89)$ & $3(33.33)$ & \\
\hline Body position before AIS, $n(\%)$ : & & & & & & 0.674 \\
\hline Sleeping & $30(44.12)$ & $6(31.58)$ & $13(54.17)$ & $7(46.67)$ & $4(40.00)$ & \\
\hline Sitting & $14(20.59)$ & $5(26.32)$ & $4(16.67)$ & $3(20.00)$ & $2(20.00)$ & \\
\hline Standing & $2(2.94)$ & $0(0.00)$ & $0(0.00)$ & $1(6.67)$ & $1(10.00)$ & \\
\hline Walking & $22(32.35)$ & $8(42.11)$ & 7 (29.17) & $4(26.67)$ & $3(30.00)$ & \\
\hline Apgar, $n(\%)$ : & & & & & & 0.751 \\
\hline 6 & $1(1.72)$ & $0(0.00)$ & $0(0.00)$ & $0(0.00)$ & $1(11.11)$ & \\
\hline 7 & $5(8.62)$ & $1(5.88)$ & $3(17.65)$ & $1(6.67)$ & $0(0.00)$ & \\
\hline 8 & $16(27.59)$ & $5(29.41)$ & $4(23.53)$ & $4(26.67)$ & $3(33.33)$ & \\
\hline 9 & $14(24.14)$ & $4(23.53)$ & $3(17.65)$ & $4(26.67)$ & $3(33.33)$ & \\
\hline 10 & $22(37.93)$ & $7(41.18)$ & $7(41.18)$ & $6(40.00)$ & $2(22.22)$ & \\
\hline Birth weight $<2500, n(\%)$ & $6(9.84)$ & $1(5.26)$ & $4(22.22)$ & $0(0.00)$ & $1(11.11)$ & 0.110 \\
\hline Fetal age, $n(\%)$ [weeks]: & & & & & & 0.260 \\
\hline 35 & $1(1.64)$ & $0(0.00)$ & $0(0.00)$ & $0(0.00)$ & $1(10.00)$ & \\
\hline 36 & $5(8.20)$ & $1(5.26)$ & $3(17.65)$ & $1(6.67)$ & $0(0.00)$ & \\
\hline 38 & $36(59.02)$ & $12(63.16)$ & $9(52.94)$ & $9(60.00)$ & $6(60.00)$ & \\
\hline 39 & $5(8.20)$ & $2(10.53)$ & $3(17.65)$ & $0(0.00)$ & $0(0.00)$ & \\
\hline 40 & $14(22.95)$ & $4(21.05)$ & $2(11.76)$ & $5(33.33)$ & $3(30.00)$ & \\
\hline Complicated pregnancy, $n$ (\%) & $12(19.35)$ & $1(5.26)$ & $6(33.33)$ & $3(20.00)$ & $2(20.00)$ & 0.161 \\
\hline $\begin{array}{l}\text { Respiratory infection preceding } \\
\text { AIS, } n(\%)\end{array}$ & $10(12.99)$ & $3(13.04)$ & $1(4.00)$ & $4(21.05)$ & $2(20.00)$ & 0.297 \\
\hline FCA, $n(\%)$ & $48(62.34)$ & $8(34.78)$ & $20(80.00)$ & $15(78.95)$ & $5(50.00)$ & 0.003 \\
\hline Heart disease, $n(\%)$ & $12(15.58)$ & $2(8.70)$ & $7(28.00)$ & $1(5.26)$ & $2(20.00)$ & 0.135 \\
\hline Chronic diseases, $n(\%)$ & $14(25.45)$ & $1(5.56)$ & $5(35.71)$ & $6(42.86)$ & $2(22.22)$ & 0.050 \\
\hline
\end{tabular}

AIS - arterial ischemic stroke, FCA - focal cerebral arteriopathy, LACI - lacunar anterior circulation infarct, PACI-partial anterior circulation infarct, $\mathrm{POCl}$ - posterior circulation infarct, $T A C l$ - total anterior circulation infarct, SD - standard deviation.

coexisting outcomes were related to stroke subtype. A normal outcome was observed in $43 \%$ children with $\mathrm{LACl}, 30 \%$ with $\mathrm{POCl}, 16 \%$ with $\mathrm{PACl}$ and only in one child with TACl. Most children with $\mathrm{LACl}$ and $\mathrm{PACl}$ had one deficit $(52 \%$ and $63 \%$, respectively), while most children with TACI had two or more consequences. When types of consequence were analyzed, we observed hemiparesis in almost all children with $\mathrm{TACl}$ stroke, less frequently in children with PACI 
Table II. Number of infarct foci, location of morphological changes and AIS symptoms in the study group

\begin{tabular}{|c|c|c|c|c|c|c|}
\hline Variable & Total & $\mathrm{LACl}$ & TACl & $\mathrm{PACl}$ & $\mathrm{POCl}$ & $P$-value \\
\hline Number of infarct foci: & & & & & & 0.068 \\
\hline 1 & $61(82.43)$ & $22(95.65)$ & $17(70.83)$ & $17(94.44)$ & $5(55.56)$ & \\
\hline 2 & $8(10.81)$ & $1(4.25)$ & $3(12.50)$ & $1(5.56)$ & $3(33.33)$ & \\
\hline$\geq 3$ & $5(6.76)$ & $0(0.00)$ & $4(16.67)$ & $0(0.00)$ & $1(11.11)$ & \\
\hline \multicolumn{6}{|c|}{ Number of locations of morphological changes: } & 0.004 \\
\hline One & $48(64.86)$ & $20(86.96)$ & $9(39.13)$ & $11(61.11)$ & $8(80.00)$ & \\
\hline Several & $26(35.14)$ & $3(13.04)$ & $14(60.87)$ & $7(38.89)$ & $2(20.00)$ & \\
\hline \multicolumn{7}{|c|}{ Neurological symptoms of AIS: } \\
\hline Hemiplegia & $9(14.75)$ & $1(5.26)$ & $5(33.33)$ & $3(15.79)$ & $0(0.00)$ & 0.056 \\
\hline Hemiparesis & $64(85.33)$ & $21(91.30)$ & $20(83.33)$ & $16(88.89)$ & $7(70.00)$ & 0.468 \\
\hline Nerve VII paralysis & $43(56.58)$ & $12(52.17)$ & $16(64.00)$ & $13(68.42)$ & $2(22.22)$ & 0.098 \\
\hline $\begin{array}{l}\text { Disturbances } \\
\text { of consciousness }\end{array}$ & $55(72.37)$ & $15(65.22)$ & $21(84.00)$ & $12(63.16)$ & $7(77.78)$ & 0.341 \\
\hline $\begin{array}{l}\text { Headache } \\
\text { and dizziness }\end{array}$ & $24(31.58)$ & $7(30.43)$ & $8(32.00)$ & $5(26.32)$ & $4(44.44)$ & 0.821 \\
\hline Aphasia & $28(37.33)$ & $9(39.13)$ & $11(44.00)$ & $4(21.05)$ & $4(50.00)$ & 0.338 \\
\hline Convulsions & $12(15.79)$ & $2(8.70)$ & $4(16.00)$ & $3(15.79)$ & $3(33.33)$ & 0.442 \\
\hline
\end{tabular}

AIS - arterial ischemic stroke, FCA - focal cerebral arteriopathy, LACI - lacunar anterior circulation infarct, PACI-partial anterior circulation infarct, $\mathrm{POCl}$ - posterior circulation infarct, $\mathrm{TACl}$ - total anterior circulation infarct.

(two thirds), and in almost $50 \%$ of children with $\mathrm{LACl}$ or $\mathrm{POCl}$.

Seizures (early and late seizures were analyzed jointly) were present in $40 \%$ of patients with $\mathrm{TACl}$, in $30 \%$ of patients with $\mathrm{POCl}$, in $26 \%$ of patients with $\mathrm{PACl}$, and in $9 \%$ of patients with $\mathrm{LACl}$ stroke. Aphasia occurred in every fifth child with TACl or $\mathrm{POCl}$, in one child with $\mathrm{PACl}$, and in none of the children with $\mathrm{LACl}$. When we analyzed coexisting consequences, we observed that a normal outcome or only hemiparesis was present with equal frequency, each in $43 \%$ of patients with $\mathrm{LACl}$ stroke, while in children with $\mathrm{TACl}$ the most frequent was hemiparesis (40\%) or hemiparesis and seizures (32\%), and in almost $50 \%$ of children with $\mathrm{PACl}$ only hemiparesis was found.

Additionally, we divided the entire study group into two subgroups: a subgroup with a normal outcome $(n=17)$ and a subgroup with at least one post-stroke consequence $(n=60)$. Table IV shows the comparison between the two subgroups. In the case of age at AIS onset, a significant difference was observed between subgroups. Children with a normal outcome were older at the time of brain ischemia. The OR value for age equaled 0.894 and shows that the odds of outcomes after ischemic stroke decreases by an average of $10.6 \%$ if the child is 1 year older at the time of stroke occurrence. In the case of birth weight, as well as the number of morphological changes, the localizations were different between the subgroups and bordered on significance. In every child with hemiplegia as a stroke symptom, it evolved into hemiparesis at follow-up.

\section{Discussion}

Arterial ischemic stroke in childhood is a rare, multifactorial disease; thus its occurrence, development and consequences may be the result of the simultaneous presence of several related risk factors.

Previously, focal cerebral arteriopathy has been recognized as a frequent risk factor for childhood stroke. Focal cerebral arteriopathy was also observed to be related to post-stroke seizures $[8,9]$. Amlie-Lefond et al. observed seizures in $23 \%$ of arteriopathy patients [6]. In Polish patients, FCA was found to be a strong predictor of post-stroke epilepsy ( $p=0.010, \mathrm{HR}=10.50)$ [9]. In the present study, $13 \%$ of patients developed post-stroke epilepsy while other available data demonstrated even greater frequencies $[10,11]$, which appear to be related to geographical differences. In the study of deVeber et al. [3] seizures were extremely high in neonates (88\%), and 37\% of older children also experienced seizures. We also observed that the presence of any type of seizures after stroke (early or late) may depend 
Table III. Neurological consequences following pediatric AIS

\begin{tabular}{|c|c|c|c|c|c|c|}
\hline Variable & Total & $\mathrm{LACl}$ & $\mathrm{TACl}$ & $\mathrm{PACl}$ & $\mathrm{POCl}$ & $P$-value \\
\hline Number of consequences: & & & & & & 0.002 \\
\hline 0 & $17(22.08)$ & $10(43.48)$ & $1(4.00)$ & $3(15.79)$ & $3(30.00)$ & \\
\hline 1 & $38(49.35)$ & $12(52.17)$ & $10(40.00)$ & $12(63.16)$ & $3(30.00)$ & \\
\hline 2 & $17(22.08)$ & $1(4.35)$ & $11(44.00)$ & $4(21.05)$ & $2(20.00)$ & \\
\hline 3 & $4(5.19)$ & $0(0.00)$ & $2(8.00)$ & $0(0.00)$ & $2(20.00)$ & \\
\hline 4 & $1(1.30)$ & $0(0.00)$ & $1(4.00)$ & $0(0.00)$ & $0(0.00)$ & \\
\hline \multicolumn{7}{|l|}{ Type of consequences: } \\
\hline Hemiparesis & $53(68.83)$ & $11(47.83)$ & $24(96.00)$ & $13(68.42)$ & $5(50.00)$ & 0.001 \\
\hline Seizures & $20(25.97)$ & $2(8.70)$ & $10(40.00)$ & $5(26.32)$ & $3(30.00)$ & 0.077 \\
\hline Aphasia & $8(10.39)$ & $0(0.00)$ & $5(20.00)$ & $1(5.26)$ & $2(20.00)$ & 0.037 \\
\hline $\begin{array}{l}\text { Other movement } \\
\text { disorders }\end{array}$ & $7(9.10)$ & $1(4.35)$ & $3(12.00)$ & $1(5.26)$ & $2(20.00)$ & 0.476 \\
\hline Coexisting consequences: & & & & & & 0.008 \\
\hline None & $17(22.08)$ & $10(43.48)$ & $1(4.00)$ & $3(15.79)$ & $3(30.00)$ & \\
\hline Hemiparesis only & $31(40.26)$ & $10(43.48)$ & $10(40.00)$ & $9(47.37)$ & $2(20.00)$ & \\
\hline $\begin{array}{l}\text { Hemiparesis } \\
\text { and seizures }\end{array}$ & $11(14.29)$ & $0(0.00)$ & $8(32.00)$ & $3(15.79)$ & $0(0.00)$ & \\
\hline Seizures only & $5(6.49)$ & $2(8.70)$ & $0(0.00)$ & $2(10.53)$ & $1(10.00)$ & \\
\hline $\begin{array}{l}\text { Hemiparesis } \\
\text { and aphasia }\end{array}$ & $4(5.19)$ & $0(0.00)$ & $2(8.00)$ & $1(5.26)$ & $1(10.00)$ & \\
\hline $\begin{array}{l}\text { Hemiparesis and other } \\
\text { movement disorders }\end{array}$ & $2(2.60)$ & $1(4.35)$ & $1(4.00)$ & $0(0.00)$ & $0(0.00)$ & \\
\hline $\begin{array}{l}\text { Hemiparesis, seizures } \\
\text { and other movement } \\
\text { disorders }\end{array}$ & $2(2.60)$ & $0(0.00)$ & $0(0.00)$ & $0(0.00)$ & $2(10.00)$ & \\
\hline $\begin{array}{l}\text { Other movement } \\
\text { disorders only }\end{array}$ & $1(1.30)$ & $0(0.00)$ & $0(0.00)$ & $1(5.26)$ & $0(0.00)$ & \\
\hline Aphasia only & $1(1.30)$ & $0(0.00)$ & $0(0.00)$ & $0(0.00)$ & $1(10.00)$ & \\
\hline $\begin{array}{l}\text { Hemiparesis, aphasia } \\
\text { and other movement } \\
\text { disorders }\end{array}$ & $1(1.30)$ & $0(0.00)$ & $1(4.00)$ & $0(0.00)$ & $0(0.00)$ & \\
\hline $\begin{array}{l}\text { Hemiparesis, seizures } \\
\text { and aphasia }\end{array}$ & $1(1.30)$ & $0(0.00)$ & $1(4.00)$ & $0(0.00)$ & $0(0.00)$ & \\
\hline $\begin{array}{l}\text { All } 4 \text { analyzed } \\
\text { consequences }\end{array}$ & $1(1.30)$ & $0(0.00)$ & $1(4.00)$ & $0(0.00)$ & $0(0.00)$ & \\
\hline
\end{tabular}

AIS - arterial ischemic stroke, $L A C I$ - lacunar anterior circulation infarct, PACl - partial anterior circulation infarct, POCI - posterior circulation infarct, TACl - total anterior circulation infarct.

on stroke subtype (the difference was close to significance, $p=0.077$ ). Seizures were most common in patients with $\mathrm{TACl}$ and least common in children with LACI stroke. In most children with AIS, FCA was transient although at least some of the factors contributing to the onset of FCA were constant and unmodified, such as genetically determined factors associated with coagulation. Presumably both, environmental factors, such as upper respiratory tract infections and some ge- netic risk factors, may precede the onset of AIS in children.

Due to the heterogeneity of AIS, different sets of genetic and non-genetic risk factors may exist and be related to the etiology and neurological burden of the disease in different populations. Among these factors, thrombophilia, hyperhomocysteinemia, dyslipidemia or MTHFR, FII, or FV gene polymorphisms can be distinguished [12-14]. Previous multicenter genetic studies, of 80 children 
Table IV. Comparisons between cases with a normal outcome and those with at least one neurological consequence

\begin{tabular}{|c|c|c|c|}
\hline Parameter & Normal outcome & At least one consequence & $P$-value \\
\hline \multicolumn{3}{|l|}{ Sex, $n(\%):$} & 0.971 \\
\hline Girls & $7(21.88)$ & $25(78.13)$ & \\
\hline Boys & $10(22.22)$ & $35(77.78)$ & \\
\hline Age, mean \pm SD [years] & $10.7 \pm 5.2$ & $7.6 \pm 5.5$ & 0.035 \\
\hline \multicolumn{3}{|l|}{ Birth weight, $n(\%)$ [g]: } & 0.068 \\
\hline$<2500$ & $0(0.00)$ & $6(100.00)$ & \\
\hline$\geq 2500$ & $14(25.45)$ & $14(74.55)$ & \\
\hline \multicolumn{3}{|l|}{ Pregnancy, $n(\%)$ : } & 0.194 \\
\hline Complicated & $1(8.33)$ & $11(91.67)$ & \\
\hline Not complicated & $12(24.00)$ & $38(76.00)$ & \\
\hline Infection preceding AIS, $n$ (\%) & $2(20.00)$ & $8(80.00)$ & 0.865 \\
\hline No infection, $n(\%)$ & $15(22.39)$ & $52(77.61)$ & \\
\hline $39(81.25)$ & $9(18.75)$ & $39(81.25)$ & 0.365 \\
\hline No FCA, $n(\%)$ & $8(27.59)$ & $21(72.41)$ & \\
\hline Heart disease, $n$ (\%) & $1(8.33)$ & $11(91.67)$ & 0.172 \\
\hline No heart disease, $n(\%)$ & $16(24.62)$ & $49(75.38)$ & \\
\hline Chronic diseases, $n$ (\%) & $2(14.29)$ & $12(85.71)$ & 0.246 \\
\hline No chronic diseases, $n$ (\%) & $12(29.27)$ & $29(70.73)$ & \\
\hline \multicolumn{3}{|l|}{ Number of infarct foci: } & 0.534 \\
\hline 1 & $14(22.95)$ & $47(77.05)$ & \\
\hline$\geq 2$ & $2(15.38)$ & $11(84.62)$ & \\
\hline \multicolumn{3}{|c|}{ Number of locations of morphological changes: } & 0.073 \\
\hline One & $14(29.17)$ & $34(70.83)$ & \\
\hline Several & $3(11.54)$ & $23(88.46)$ & \\
\hline
\end{tabular}

AIS - arterial ischemic stroke, FCA - focal cerebral arteriopathy, LACI - lacunar anterior circulation infarct, PACI - partial anterior circulation infarct, $\mathrm{POCl}$ - posterior circulation infarct, $T A C l$ - total anterior circulation infarct, SD - standard deviation.

suffering from AIS, showed that post-stroke epilepsy may be correlated with carrier state of the $\mathrm{G}$ allele of the $-174 \mathrm{G}>\mathrm{C}$ polymorphism within the IL-6 gene [15]. On the other hand, our earlier pilot data also provided some indication of an association between other candidate polymorphisms (561A>C in the E-selectin gene or insertion-deletion polymorphism of the ACE gene) and a serious post-stroke state with noticeable consequences $[16,17]$. However, both of the studies were based on a small number of patients and have not been confirmed in a larger group.

In the present study, we observed that AIS is more common in boys than girls ( $58 \%$ vs. $42 \%$ ) and these frequencies are in agreement with other findings [18]. Westmacott et al. [19] demonstrat- ed that particularly boys with unilateral neonatal stroke are at increased risk for cognitive deficits during the school years. A possible explanation for this may be the immaturity of the male brain at birth compared to the female one, with its particular susceptibility to damage caused by stroke [19]. At present, we found significant differences in sex distribution between the stroke subtypes $(p=0.030)$. Most children with $\mathrm{POCl}$ and TACl stroke subtypes were male. Interestingly, there might be some genetic determinants of AIS development dependent on gender. Earlier, the $677 \mathrm{C}>\mathrm{T}$ polymorphism within the MTHFR gene was suggested to significantly increase the risk of AIS in boys [20].

Arterial ischemic stroke in our patients appeared most frequently in winter (34\%), then au- 
tumn (23\%) and in summer and spring with the same frequency (22\%). In adults, low ambient temperature of the day of stroke onset increased the risk of ischemic stroke as well as high-speed wind, especially in older patients [21]. Higher frequency of stroke in winter or autumn may also be linked with the greater frequency of infections, which are common in the colder seasons of the year. It was demonstrated that the risk of pediatric AIS is increased by infections [22]. Previously, it was observed that major infections (e.g. bacterial meningitis or sepsis) have been associated with stroke in children. However, minor infections, mostly upper respiratory tract infections, occur more frequently in childhood [23, 24]. Infections were demonstrated to be related to stroke in adults since they were observed in $10 \%$ of adults with AIS [23]. Minor infections may affect the prothrombotic state, which is caused by inflammatory mediators [25] and may lead to hypercoagulability. In most studies, frequency of the prothrombotic state ranged from $20 \%$ to $50 \%$ in children [26]. A significantly elevated level of procalcitonin was suggested to be a sensitive and specific predictor of systemic bacterial infection in children with chronic kidney disease [27]. In our study, in almost $13 \%$ of children respiratory infections preceded ischemic stroke. In $60 \%$ of them, AIS appeared in the autumn-winter period.

The factors related to pregnancy and childbirth did not differ between the analyzed stroke subgroups, and $38 \%$ of children obtained 10 Apgar points after birth. The available data indicate that most children suffering from AIS usually come from well-conceived, full-term pregnancy and the newborns usually have good Apgar scores and show normal somatic development [28].

We demonstrated that number, type and coexisting consequences were related to stroke subtype. In our study, $22 \%$ of analyzed children were characterized by a normal outcome without deterioration, while a single deficit was present in $49 \%$ of patients and two, three or four consequences were present in $29 \%$ of patients. Sreenan et al. [29] observed a normal outcome in $32 \%$ of children with perinatal stroke, while single or multiple deficits were demonstrated in $17 \%$ and $50 \%$, respectively. We observed significant differences in the presence of hemiparesis in the analyzed subgroups of patients. Hemiparesis affected almost all children with $\mathrm{TACl}$ stroke. Additionally, in all children with hemiplegia the evolution to hemiparesis was observed. In children without hemiplegia in the acute phase of the disease, evolution of the grade of hemiparesis was observed during follow-up. When we compared children with a normal outcome and children with some neurological deficits we found that children with neurological deficits were significantly younger at the time of brain ischemia compared to children with a normal outcome. This finding is in agreement with previously published data based on patients with perinatal stroke, in which the young age of the patient at onset was significantly related to a poor neurological outcome [30]. In this study, the authors also observed infarction in the right middle cerebral artery territory as well as fever at presentation as risk factors [30].

Previously, some data concerning factors influencing stroke outcomes in adults were published. Worsened clinical outcome and increased risk of in-hospital death were associated with hyperglycemia on admission in the group of patients with ischemic and hemorrhagic stroke [31]. However, it was also observed that prior transient ischemic attacks (TIAs) may have a neuroprotective effect on the subsequent ischemic stroke, as well as neurological outcomes [32].

The limitation of our study is the rather low number of patients, which is mainly due to the fact that they were recruited from a single medical center. Additionally, we did not consider the inherited issues of cardiovascular diseases or abnormalities in lipid or fibrinogen levels in the analyzed patients, whereas those problems are of great importance in regard to the risk of AIS [33-36].

In conclusion, our study shows that the presence and number of neurological outcomes depend on stroke subtypes. There is also a significant relationship between the presence of post-stroke deficits and age at onset. Children with at least one deficit were younger at the time of AIS occurring than children with a normal outcome. However, further studies are needed to confirm and identify these patterns and associations.

\section{Conflict of interest}

The authors declare no conflict of interest.

\section{References}

1. Lopez-Vicente M, Ortega-Gutierrez S, Amlie-Lefond C, Torbey MT. Diagnosis and management of pediatric arterial ischemic stroke. J Stroke Cerebrovasc Dis 2010; 19: $175-83$.

2. Nowak-Gottl U, Gunther G, Kurnik K, Strater R, Kirkham F. Arterial ischemic stroke in neonates, infants, and children: an overview of underlying conditions, imaging methods, and treatment modalities. Semin Thromb Hemost 2003; 29: 405-14.

3. deVeber GA, Kirton A, Booth FA, et al. Epidemiology and outcomes of arterial ischemic stroke in children: the $\mathrm{Ca}$ nadian Pediatric Ischemic Stroke Registry. Pediatr Neurol 2017; 69: 58-70.

4. Westmacott R, Askalan R, MacGregor D, Anderson P, Deveber $\mathrm{G}$. Cognitive outcome following unilateral arterial ischaemic stroke in childhood: effects of age at stroke 
and lesion location. Dev Med Child Neurol 2010; 52: 386-93.

5. Ballantyne AO, Spilkin AM, Hesselink J, Trauner DA. Plasticity in the developing brain: intellectual, language and academic functions in children with ischaemic perinatal stroke. Brain 2008; 131: 2975-85.

6. Amlie-Lefond C, Bernard TJ, Sébire G, et al.; International Pediatric Stroke Study Group. Predictors of cerebral arteriopathy in children with arterial ischemic stroke: results of the International Pediatric Stroke Study. Circulation 2009; 119: 1417-23.

7. Bamford J, Dennis M, Sandercock M, Burn J, Warlow C. The frequency, causes and timing of death within 30 days of the first stroke: the Oxfordshire Community Stroke Project. J Neurol Neurosurg Psychiatry 1990; 53: 824-9.

8. Beslow LA, Abend NS, Gindville MC, et al. Pediatric intracerebral hemorrhage: acute symptomatic seizures and epilepsy. JAMA Neurol 2013; 70: 448-54.

9. Kopyta I, Sarecka-Hujar B, Skrzypek M. Post-stroke epilepsy in Polish paediatric patients. Dev Med Child Neurol 2015; 57: 821-8.

10. Lee EH, Yum MS, Ko TS. Risk factors and clinical outcomes of childhood ischemic stroke in a single Korean tertiary care center. J Child Neurol 2012; 27: 485-91.

11. Morais NM, Ranzan J, Riesgo RS. Predictors of epilepsy in children with cerebrovascular disease. J Child Neurol 2013; 28: 1387-91.

12. Sarecka-Hujar B, Kopyta I, Skrzypek M, Sordyl J. Association between the $20210 \mathrm{G}>\mathrm{A}$ prothrombin gene polymorphism and arterial ischemic stroke in children and young adults-two meta-analyses of 3586 cases and 6440 control subjects in total. Pediatr Neurol 2017; 69: 93-101.

13. Sulima $M$, Lewicka $M$, Kozak K, et al. Characteristics of causes of thrombophilia. Eur J Med Tech 2017; 2: 62-8.

14. Kopyta I, Zimny M, Sarecka-Hujar B. The role of biochemical risk factors in the etiology of AIS in children and adults. Int J Neurosci 2015; 125: 875-84.

15. Balcerzyk A, Nowak M, Kopyta I, et al. Impact of the $-174 \mathrm{G} / \mathrm{C}$ interleukin-6 (IL-6) gene polymorphism on the risk of paediatric ischemic stroke, its symptoms and outcome. Folia Neuropathol 2012; 50: 147-51.

16. Żak I, Sarecka B, Balcerzyk A, et al. E-selectin gene Pst $561 \mathrm{~A}>C$ polymorphism and brain ischemic stroke in children: association pilot-study. Part one. Neurol Dziec 2006; 13: 23-30.

17. Żak I, Balcerzyk A, Sarecka B, et al. Epsilon polymorphism of apolipoprotein $\mathrm{E}$ gene and insertion-deletion polymorphism of ACE gene and brain ischemic stroke in children: association pilot-study. Neurol Dziec 2005; 14: 15-24.

18. Golomb MR, Fullerton HJ, Nowak-Gottl U, Deveber G; International Pediatric Stroke Study Group. Male predominance in childhood ischemic stroke: findings from the international pediatric stroke study. Stroke 2009; 40: $52-7$.

19. Westmacott R, MacGregor D, Askalan R, deVeber G. Late emergence of cognitive deficits after unilateral neonatal stroke. Stroke 2009; 40: 2012-9.

20. Zak I, Sarecka-Hujar B, Kopyta I, et al. The T allele of the $677 C>T$ polymorphism of methylenetetrahydrofolate reductase gene is associated with an increased risk of ischemic stroke in Polish children. J Child Neurol 2009; 24: 1262-7.

21. Tamasauskiene L, Rastenyte D, Radisauskas R, et al. Relationship of meteorological factors and acute stroke events in Kaunas (Lithuania) in 2000-2010. Environ Sci Pollut Res Int 2017; 24: 9286-93.

22. Fullerton HJ, Hills NK, Elkind MS, et al.; VIPS Investigators. Infection, vaccination, and childhood arterial ischemic stroke: results of the VIPS study. Neurology 2015 85: 1459-66.

23. Roquer J, Cuadrado-Godia E, Giralt-Steinthauer E, et al. Previous infection and stroke: a prospective study. Cerebrovasc Dis 2012; 33: 310-5.

24. Pac M, Bernatowska EA, Kierkuś J, et al. Gastrointestinal disorders next to respiratory infections as leading symptoms of $X$-linked agammaglobulinemia in children - 34-year experience of a single center. Arch Med Sci 2017; 13: 412-7.

25. Elkind MS, Cole JW. Do common infections cause stroke? Semin Neurol 2006; 26: 88-99.

26. Chan AK, de Veber G. Prothrombotic disorders and isch emic stroke in children. Semin Pediatr Neurol 2000; 7 : 301-8

27. Fadel FI, Elshamaa MF, Elghoroury EA, et al. Usefulness of serum procalcitonin as a diagnostic biomarker of infection in children with chronic kidney disease. Arch Med Sci Atheroscler Dis 2016; 1: e23-e31.

28. Raju TNK, Nelson KB, Ferriero D, Lynch JK; NICHD-NINDS Perinatal Stroke Workshop Participants. Ischemic Perinatal Stroke: summary of a workshop sponsored by the National Institute of Child Health and Human Development and the National Institute of Neurological Disorders and Stroke. Pediatrics 2007; 120: 609-16.

29. Sreenan C, Bhargava R, Robertson CM. Cerebral infarction in the term newborn: clinical presentation and long-term outcome. J Pediatr 2000; 137: 351-5.

30. Cnossen MH, Aarsen FK, Akker SL, et al. Paediatric arterial ischaemic stroke: functional outcome and risk fac tors. Dev Med Child Neurol 2010; 52: 394-9.

31. Snarska KK, Bachórzewska-Gajewska H, Kapica-Topczewska K, et al. Hyperglycemia and diabetes have different impacts on outcome of ischemic and hemorrhagic stroke. Arch Med Sci 2017; 13: 100-8.

32. Wang WW, Chen DZ, Zhao M, Yang XF, Gong DR. Prior transient ischemic attacks may have a neuroprotective effect in patients with ischemic stroke. Arch Med Sci 2017; 13: 1057-61.

33. Kopyta I, Sarecka-Hujar B, Emich-Widera E, Marszał E Zak I. Association between lipids and fibrinogen levels and ischemic stroke in the population of the Polish children with arteriopathy and cardiac disorders. Wiad Lek 2010; 63: 17-23.

34. Myśliwiec $M$, Walczak $M$, Małecka-Tendera $E$, et al. Management of familial hypercholesterolemia in children and adolescents. Position paper of the Polish Lipid Expert Forum. J Clin Lipidol 2014; 8: 173-80.

35. Vallejo-Vaz AJ, Kondapally Seshasai SR, Cole D, et al. Familial hypercholesterolaemia: a global call to arms. Atherosclerosis 2015; 243: 257-9.

36. Vulic D, Loncar S, Ostojic M, Marinkovic J, Vulic B, Wong ND. Risk factor indicators in offspring of patients with premature coronary heart disease in Banja Luka region/Republic of Srpska/Bosnia and Herzegovina. Arch Med Sci 2016; 12: 736-41. 